\title{
A risk scoring system to predict the individual incidence of early-onset colorectal cancer
}

\author{
Jialin $\mathrm{Gu}^{1,2+}$, Yan $\mathrm{Li}^{2 \dagger}$, Jialin $\mathrm{Yu}^{1,3}$, Miao Hu${ }^{1,2}$, Yi Ji ${ }^{1,3}$, Lingchang $\mathrm{Li}^{1,3}$, Canhong Hu, ${ }^{1,3}$, Guoli Wei ${ }^{1,3,4,5^{*}}$ and \\ Jiege $\mathrm{HuO}^{1,3^{*}}$
}

\begin{abstract}
Background: The incidence of early-onset colorectal cancer (EOCRC) is increasing at an alarming rate and further studies are needed to identify risk factors and to develop prevention strategies.

Methods: Risk factors significantly associated with EOCRC were identified using meta-analysis. An individual risk appraisal model was constructed using the Rothman-Keller model. Next, a group of random data sets was generated using the binomial distribution function method, to determine nodes of risk assessment levels and to identify low, medium, and high risk populations.

Results: A total of 32,843 EOCRC patients were identified in this study, and nine significant risk factors were identified using meta-analysis, including male sex, Caucasian ethnicity, sedentary lifestyle, inflammatory bowel disease, and high intake of red meat and processed meat. After simulating the risk assessment data of 10,000 subjects, scores of 0 to $0.0018,0.0018$ to 0.0036 , and 0.0036 or more were respectively considered as low-, moderate-, and high-risk populations for the EOCRC population based on risk trends from the Rothman-Keller model.

Conclusion: This model can be used for screening of young adults to predict high risk of EOCRC and will contribute to the primary prevention strategies and the reduction of risk of developing EOCRC.
\end{abstract}

Keywords: Early-onset colorectal cancer, Risk factors, Meta-analysis, Rothman-Keller model, Risk assessment

\section{Background}

Although the incidence of colorectal cancer (CRC) has declined with the support of medical technology and prevention policies, a completely opposite trend has been observed in young adults under the age of 50 years [1, 2]. Early-onset colorectal cancer (EOCRC) is defined as colorectal cancer diagnosed before the age of 50 years, and has shown a progressively increasing incidence

\footnotetext{
*Correspondence: weiguoli1987@163.com; huojiege@jsatcm.com

†Jialin Gu and Yan Li equal first authors.

${ }^{1}$ Department of Oncology, Affiliated Hospital of Integrated Traditional Chinese and Western Medicine, Nanjing University of Chinese Medicine, 100 Cross Street, Maigaoqiao, Nanjing, Jiangsu 210028, P.R. China Full list of author information is available at the end of the article
}

worldwide. Studies have reported that approximately $11 \%$ of CRC cases registered in the National Cancer Database were diagnosed in adults aged 18 to 49 years [3]. Similarly, recent data from Europe indicate that the incidence of CRC increased by $7.9,4.9$, and $1.6 \%$ per year among subjects aged 20-29, 30-39, and 40-49years from 2004 to 2016, respectively [4]. Most cases of EOCRC are diagnosed after the onset of symptoms, which include bloody stool and abdominalgia, increasing the danger of delayed diagnosis and poor prognosis [5, 6].

The causes of the rising incidence of EOCRC have not been fully elucidated. The majority of EOCRC cases are disseminated and may be associated with changes in environmental, behavioral, and dietary patterns. Several 
studies have reported an increased risk of EOCRC from alcohol consumption, sedentary lifestyle, and high intake of red and processed meats [7-10]. In addition, lower levels of schooling may also increase the prevalence of EOCRC $[7,11]$. Primary prevention is a key strategy to reduce the burden of this disease. The American Cancer Society has lowered the age of screening for people at risk of colorectal cancer from 50 to 45 years of age [12]. Studies demonstrate that increasing participation in population-based risk screening not only reduces mortality but also reduces health care costs [13]. Therefore, it is important to identify risk factors for EOCRC. Previous meta-analyses have identified risk factors such as family history of CRC, male sex, and obesity. However, there are still other factors that have revealed non-significant associations due to small sample sizes with insufficient statistical power $[14,15]$. Due to the needs of large-scale population screening, it is essential to build an individualized risk prediction and evaluation model, which can help evaluate and identify high-risk populations for EOCRC. Previous studies have found that individualized risk-based screening is more likely to be accepted [16].

Accordingly, we established the EOCRC risk appraisal and prediction system using the Rothman-Keller model, aiming at early and effective identification of high-risk populations of EOCRC. Our scoring system also provides easy risk prediction formulas for individuals to achieve potential risk reduction.

\section{Methods}

\section{Search strategy and study selection}

Based on a previously published meta-analysis [14], we conducted a comprehensive search in PubMed and the Web of Science (WOS) to discover new original studies using the following terms: "colorectal cancer," "colorectal neoplasms," "colon tumor," "rectum tumor," "colon cancer," "rectum cancer," "early onset," "young onset," "young adult", "age of 50", "risk". Multiple combinations of the above search terms were used. Studies that met the following criteria were considered: i) Diagnosis consistent with EOCRC, ii) cohort studies or case-control studies, and iii) control group age-matched with non-EOCRC patients of the case group. Only studies published in English were considered. Literature management and review was performed using Endnote $\times 9$ (V9.3.3, Clarivate Analytics) [17]. References that met the inclusion criteria were manually screened to avoid omissions. Reviews, case reports, experimental studies, duplicate publications, and studies that did not meet the diagnosis of EOCRC were excluded. The titles, abstracts, and subsequent full text of the retrieved publications were screened by two independent reviewers. A third reviewer decided on any disagreements.

\section{Data extraction}

Baseline data were collected from all patients, including sex, race, past medical history (diabetes, inflammatory bowel disease (IBD), hyperlipidemia, hypertension), dietary factors (processed meat, red meat), lifestyle habits (sedentary, obesity, alcohol intake, smoking, dessert), and medication history (aspirin and NSAIDs). Screening of risk factors for EOCRC was derived from meta-analysis and the factors that significantly correlated with EOCRC $(P<0.05)$ were included in subsequent model construction.

\section{Construction of the risk appraisal model}

The Rothman-Keller model was used to construct an individualized risk appraisal model for EOCRC [18]. It was first applied in 1972 to assess the effects of alcohol and tobacco on the risk of oral and laryngeal cancers. It considers both independent and interactive effects of influencing factors and has been applied in the risk assessment and prevention of a multitude of chronic diseases [19]. The relative ratio (RR) can be replaced by the odds ratios (OR) when the outcome occurs in less than $10 \%[20,21]$. The computational procedure of Rothman-Keller model is as follows:

(I)Population attributable risk percentage (PAR\%)

$$
P A R \%=\frac{P_{i}\left(R R_{i}-1\right)}{P_{i}\left(R R_{i}-1\right)+1} \times 100 \%
$$

(II) Baseline incidence ratio $(\rho)$

$$
\rho=\frac{1}{\sum_{i=1}^{n} R R_{i} \times P_{i}}=1-P A R \%
$$

$P_{i}$ : the proportion of individuals exposed to a risk factor in the overall population; $R R_{i}$ : the relative risk of exposure to a risk factor.

(III) Risk score $(S)$ and combined risk score $(\theta)$

$$
\begin{aligned}
& S=\rho \times R R_{i} \\
& \theta=\left(M_{1}-1\right)+\left(M_{2}-1\right)+\Lambda+\left(M_{n}-1\right)+N_{1} \times N_{2} \times \Lambda \times N_{i}
\end{aligned}
$$

$M_{i}:$ risk factor scores for $S \geq 1 ; N_{i}$ : risk factor scores for $S<1$

(IV) Individual risk prediction score of EOCRC (I) 


$$
I=Q_{E O C R C} \times \theta
$$

$Q_{\text {EOCRC: }}$ The incidence of EOCRC.

\section{Statistical analysis}

We performed sensitivity analysis on variables that were significant. Only variables that showed significance $(P<0.05)$ in the fixed-effects model combined with the random-effects model were considered stable. These eligible variables were then included in the risk scoring system. Variables that exhibit significance in only one model will be excluded from the risk system since they were considered to be unstable [19]. The risk of publication bias was calculated using Egger's test. Simulated data of 10,000 subjects were randomly generated using the binomial distribution function method. The individual risk prediction scores of EOCRC $(I)$ were calculated after substitution of the simulated data into the RothmanKeller model. Statistical analysis was performed using STATA 15.1 software (Stata Corporation, College Station, TX, USA) and RStudio software (version 1.4).

\section{Results}

\section{Literature selection}

The literature search identified 4312 publications, of which 3846 were unique studies. A total of 3744 publications were excluded because they did not meet the inclusion criteria. After screening the full text of the remaining 102 studies, 18 articles were included in the meta-analysis, four of which were new compared to the previously published meta-analysis. Ten studies were used for the construction of the risk appraisal model as they provided baseline data of case and control groups, containing a total of 32,843 cases and 25,806,408 controls. Figure 1 shows the flow chart of the study selection and identification.

\section{Risk factors for EOCRC}

As shown in Table 1, based on the combined ORs and $P$-values, we identified nine core risk factors influencing the development of EOCRC, namely male sex, Caucasian ethnicity, family history of CRC, sedentary behavior, alcohol intake, obesity, diabetes, IBD, and high intake of red meat. However, the use of NSAIDs or aspirin and high intake of dessert were excluded due to the lack of sufficient studies $(n=2)$. The results of the fixed-effects and random-effects models showed that the joint effect of smoking, hypertension, hyperlipidemia, and educational level was unstable ( $P$ for fixedeffects model $<0.05$ while $P$ for random-effects model $>0.05)$. Thus, these factors were excluded in the Rothman-Keller model. In addition, although high intake of processed meat did not show a significant association in the meta-analysis, it was included in the construction of the prediction model as a potential factor for EOCRC because it showed a significant trend $(\mathrm{OR}=1.24,95 \%$ $\mathrm{CI}=0.99-1.55)$. No publication bias was found using Egger's test $(P>0.05)$.

\section{Parameters of the risk appraisal model}

The proportion of exposed individuals in the control group was used as an estimate of the overall population exposure rate $\left(P_{i}\right)$. The RR values $(R R s)$ in the RothmanKeller model were replaced by the combined OR values $\left(O R_{i}\right)$ from the meta-analysis. The parameters of the EOCRC risk appraisal model are shown in Table 2.

\section{Calculation of the EOCRC individualized risk assessment}

Individualized combined risk scores $(I)$ were calculated based on the parameters in Table 2 (Formula III and IV). For example, a male subject (subject A) younger than age 50 years $(S=1.0970)$, Caucasian $(S=1.1361)$, with a family history of CRC $(S=3.8175)$, history of alcohol consumption $(S=1.3513)$, diabetes $(S=1.2391)$, and high intake of red meat $(S=1.0685)$, but without the characteristics of IBD $(S=0.9314)$, sedentary lifestyle $(S=0.9507)$, obesity $(S=0.8833)$, and high intake of processed meat $(S=0.9171)$. Accordingly, the combined risk score $(\theta)$ of subject $\mathrm{A}=(1.0970-1)+(1.1361-$ $1)+(3.8175-1)+(1.3513-1)+(1.2391-1)+(1.0685-$ $1)+0.9314 \times 0.9507 \times 0.8833 \times 0.9171=4.427$. A study based on the U.S. Surveillance, Epidemiology, and End Results (SEER) database reported a $0.12 \%$ prevalence of EOCRC [8]. Therefore, the individual risk prediction score of EOCRC $(I)$ for subject $\mathrm{A}=0.12 \%$ * $4.427=0.531 \%$.

\section{Level of EOCRC risk assessment}

Figure 2 and Supplementary Table 1 show the individual risk scores of 10,000 simulated subjects sorted in ascending order. The 8795th $(I=0.0018$, point A) and 9591st $(I=0.0036$, point B) positions were selected as the nodes for the level of EOCRC risk assessment. Individual risk prediction scores $(I)$ of 0 to $0.0018,0.0018$ to 0.0036 , and 0.0036 or higher were considered low, medium, or high risk. Accordingly, Subject A was in a high-risk group, and we strongly recommend that he should receive health education and clinical screening.

\section{Discussion}

Although CRC is still relatively rare in the younger aged population $(0.12 \%)$, the alarming increasing in EOCRC patients cannot be ignored $[29,30]$. The clinical cases, molecular, and familial features of EOCRC strongly 


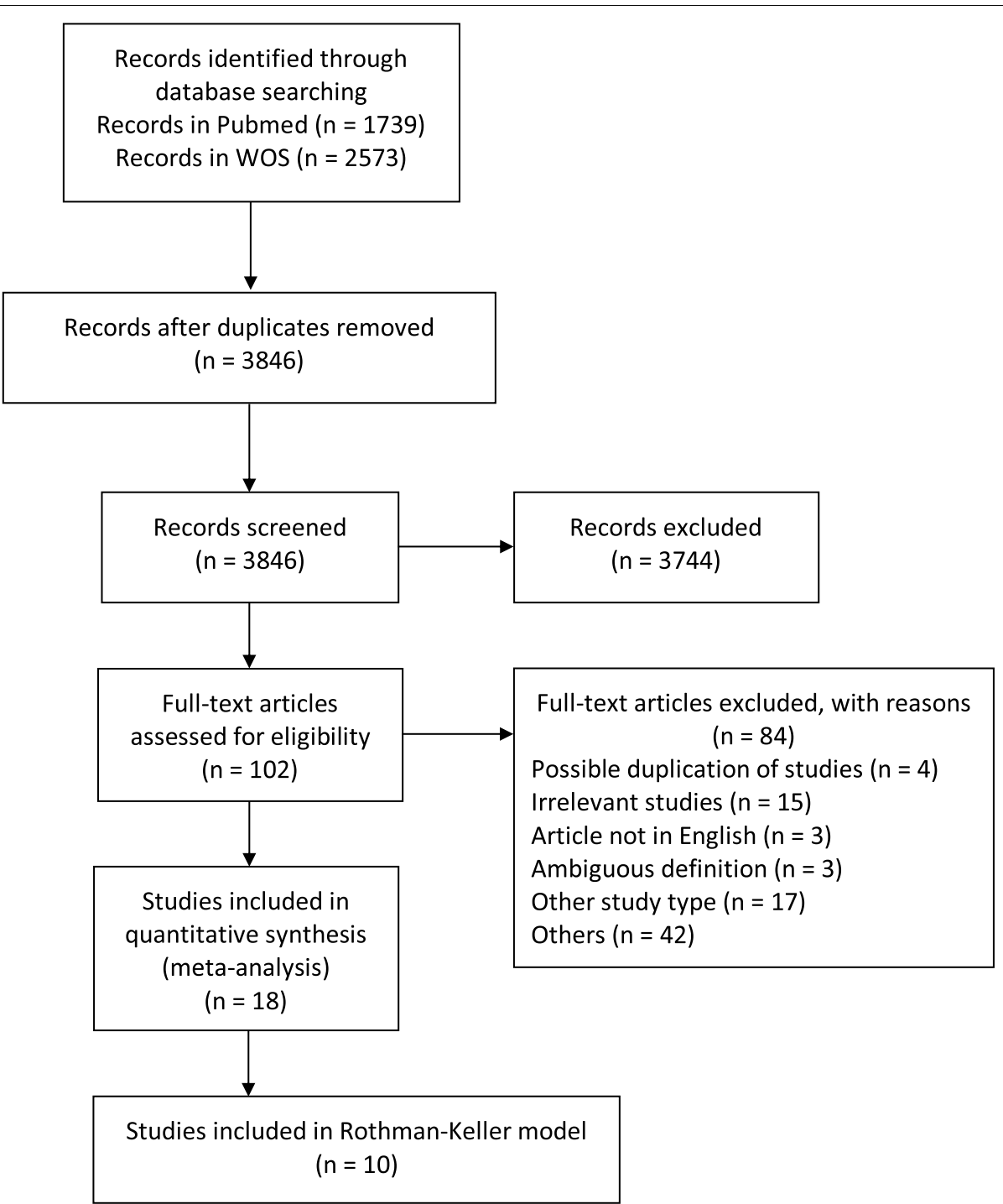

Fig. 1 The flow chart of the study selection and identification

suggest that it may be a separate disease rather than a subset of CRC [31, 32]. It is estimated that there may be a $30-120 \%$ increase in young colorectal cancer patients by 2030 based on current trends [33]. In addition, most EOCRCs are insidious and have a worse prognosis compared to late-onset CRC, which undoubtedly increases the difficulty of diagnosis and disease prevention [34]. Although annual screening is strongly recommended for individuals with a family history of CRC in first-degree relatives, the lack of subjective knowledge about the high risks of CRC and the negative attitudes towards clinical screening are the main reasons why most young adults are reluctant to undergo screening, which undoubtedly increases the difficulty of primary prevention in high-risk groups [35, 36]. It is important to construct a risk assessment system based on clinical or behavioral factors. Previous studies have developed clinical prediction models based on colonoscopy or stool test results [37-39]. Although such tests identify a subset of patients that may benefit from them, most predictive tools require specialized assessment by clinicians and are not suitable for prospective population screening [40]. In addition, precise cancer screening or modified screening regimens based on risk-stratification may allow adults to benefit more from CRC screening than conventional age-based strategies [41]. Therefore, we prefer to build a risk prediction system in which subjects can independently participate, and contributes to 


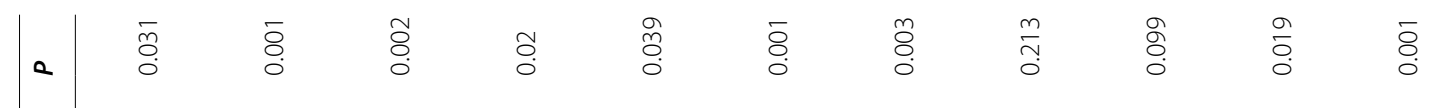

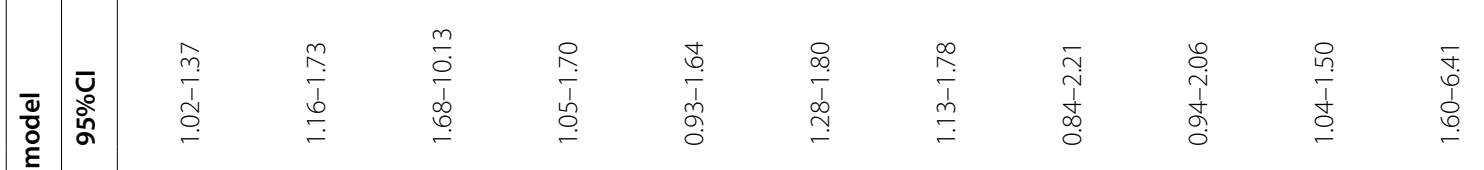

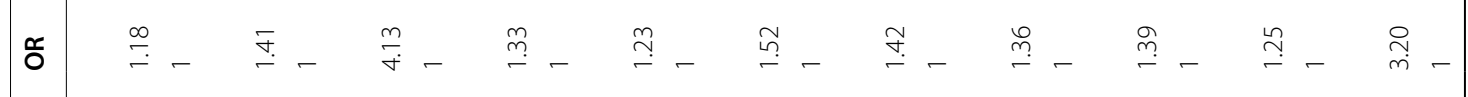

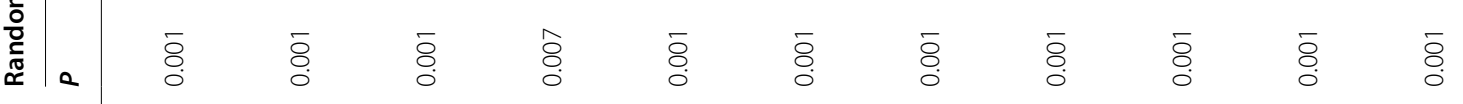

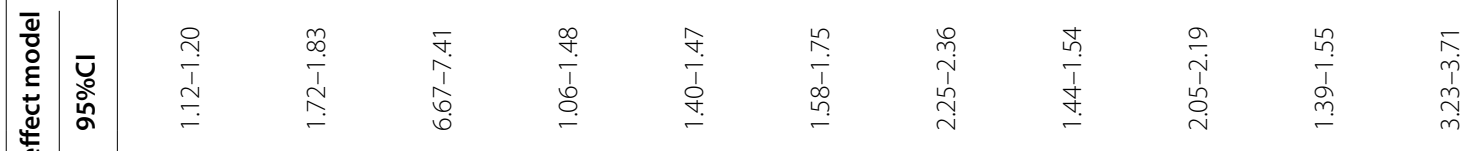
这

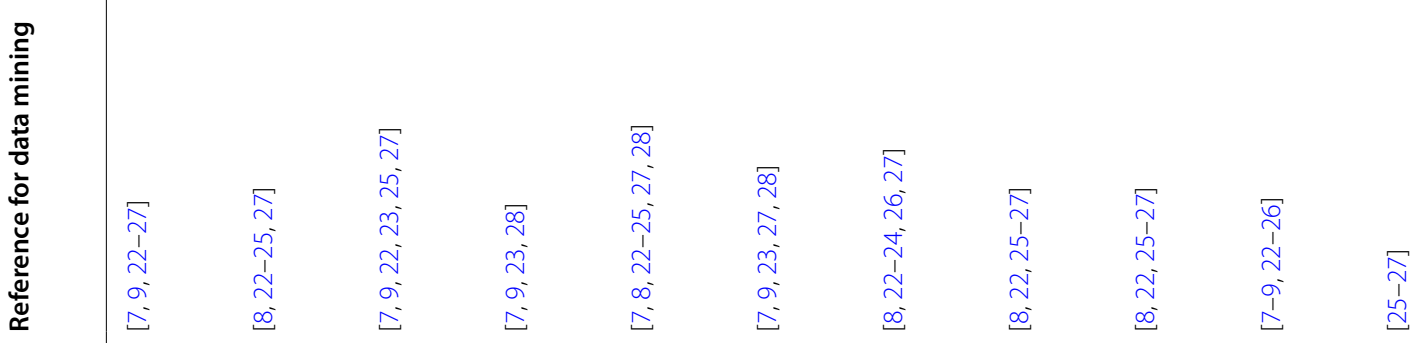




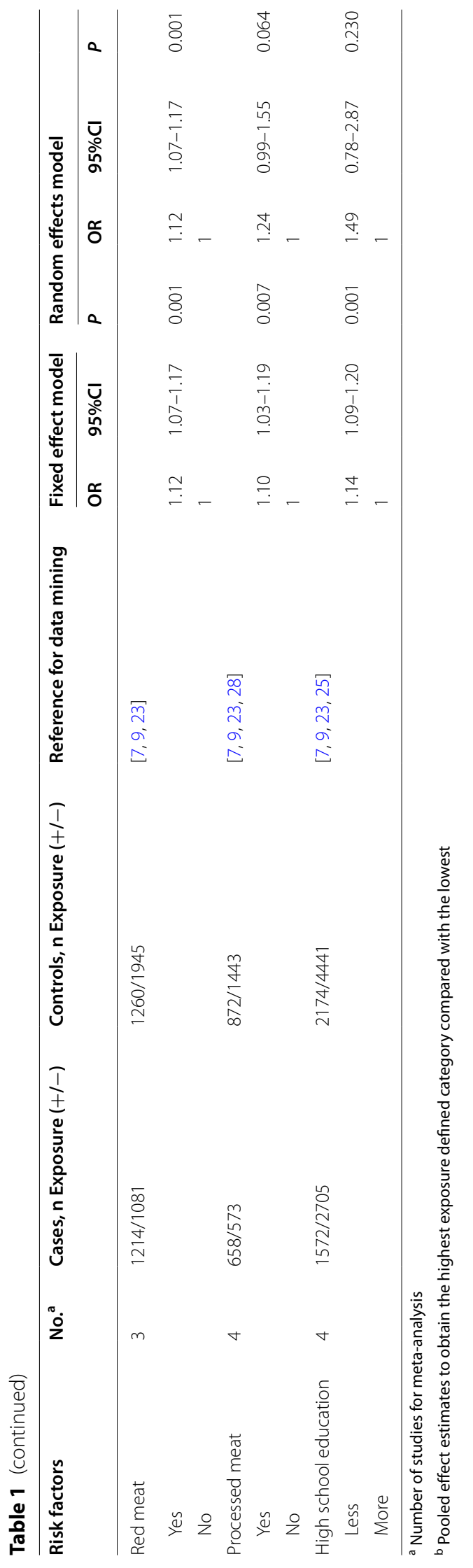


Table 2 Risk assessment model parameters of EOCRC

\begin{tabular}{|c|c|c|c|c|c|}
\hline Risk factor & $R R_{i}$ & $P_{i}$ & PAR\% & $\rho$ & $S$ \\
\hline \multicolumn{6}{|l|}{ Male } \\
\hline Yes & 1.18 & 0.4206 & 0.0704 & 0.9296 & 1.0970 \\
\hline No & 1 & 0.5794 & & & 0.9296 \\
\hline \multicolumn{6}{|c|}{ Caucasian ethnicity } \\
\hline Yes & 1.41 & 0.5880 & 0.1942 & 0.8058 & 1.1361 \\
\hline No & 1 & 0.4120 & & & 0.8058 \\
\hline \multicolumn{6}{|c|}{ Family history of CRC } \\
\hline Yes & 4.13 & 0.0262 & 0.0757 & 0.9243 & 3.8175 \\
\hline No & 1 & 0.9738 & & & 0.9243 \\
\hline \multicolumn{6}{|l|}{ Sedentary } \\
\hline Yes & 1.33 & 0.1572 & 0.0493 & 0.9507 & 1.2644 \\
\hline No & 1 & 0.8428 & & & 0.9507 \\
\hline \multicolumn{6}{|l|}{ Alcohol } \\
\hline Yes & 1.52 & 0.2401 & 0.1110 & 0.8890 & 1.3513 \\
\hline No & 1 & 0.7599 & & & 0.8890 \\
\hline \multicolumn{6}{|l|}{ Obesity } \\
\hline Yes & 1.42 & 0.3146 & 0.1167 & 0.8833 & 1.2543 \\
\hline No & 1 & 0.6854 & & & 0.8833 \\
\hline \multicolumn{6}{|l|}{ Diabetes } \\
\hline Yes & 1.25 & 0.0353 & 0.0087 & 0.9913 & 1.2391 \\
\hline No & 1 & 0.9647 & & & 0.9913 \\
\hline \multicolumn{6}{|l|}{$\mathrm{IBD}$} \\
\hline Yes & 3.2 & 0.0335 & 0.0686 & 0.9314 & 2.9806 \\
\hline No & 1 & 0.9665 & & & 0.9314 \\
\hline \multicolumn{6}{|l|}{ Red meat } \\
\hline Yes & 1.12 & 0.3931 & 0.0451 & 0.9549 & 1.0695 \\
\hline No & 1 & 0.6069 & & & 0.9549 \\
\hline \multicolumn{6}{|c|}{ Processed meat } \\
\hline Yes & 1.24 & 0.3767 & 0.0829 & 0.9171 & 1.1372 \\
\hline No & 1 & 0.6233 & & & 0.9171 \\
\hline
\end{tabular}

encouraging young adults to screen for potential disease probability before visiting the clinic.

Compared to the previous meta-analysis [14], we identified significant associations between sedentary, IBD, diabetes, high intake of red meat and processed meat, and the development of EOCRC, as we included more original studies. Although the correlation between the high intake of processed meats and EOCRC was not statistically significant, the trend it exhibited was equally alarming [42]. The role of non-genetic factors, especially dietary factors, in the pathogenesis of EOCRC should not be ignored. Several studies have also reported a positive association between reduced intake of folate, fiber, citrus fruits, and greater risk of EOCRC [7, 9]. Unfortunately, most studies do not include regional factors as one of the variables, which prevents us from understanding the contribution of urban-rural or regional differences to the incidence of EOCRC, although this appears to be potentially relevant at present [43-45]. Our study constructed a more accurate model based on a meta-analysis that considered and quantified interactions among risk factors, providing a prediction system for individuals under the age of 50 years. In contrast to non-modifiable factors such as sex and race, most risk factors we identified were common and changeable behavioral factors, such as sedentary lifestyle, high intake of red meat and processed meat, and alcohol consumption. This means that young subjects who are alerted may reduce the incidence of EOCRC by modifying their diet or daily behavior patterns. As far as we know, most people appear to be more receptive to modifying their personal risk through diet and exercise [16]. Despite the prevalence of these factors among the general CRC population, we can still find some evidence on how these variables influence the development of EOCRC. It is well known that family history of cancer, obesity, sedentary lifestyle and high consumption of high calorie, high fat, high sucrose diet are the key factors in CRC [46]. The prevalence of obesity has increased in the USA, especially among young patients, which may play a role in reducing the age of CRC onset [33]. Similar problems exist in other countries $[47,48]$. The prevalence of known risk factors such as diabetes, smoking, and alcohol consumption continues to rise [49-51], and these high-risk behaviors in young adults increase the incidence of EOCRC despite measures already in place to counter. Patients with longstanding IBD have a two to three times increased risk of CRC, especially when diagnosed at an early age [52]. Approximately $2-5 \%$ of the general CRC population is affected by hereditary cancer syndromes. However, this appears to be higher (22\%) in patients diagnosed with EOCRC [2]. Besides, the increasing global prevalence of non-Mediterranean Western dietary patterns, characterized by a high intake of red and processed meats, among the young population has undoubtedly increased the burden of EOCRC [53]. Therefore, there is a significant need to enhance health education to control these potential risk factors.

This study had some limitations. First, although we generated a group of random data sets using a binomial distribution method, there is a lack of evidence supporting and validating results from multicenter, large-scale, and real-world studies. Second, studies on risk factors for EOCRC are still very limited and lead to the exclusion of other potential risk factors from the model construction due to insufficient statistical power. 


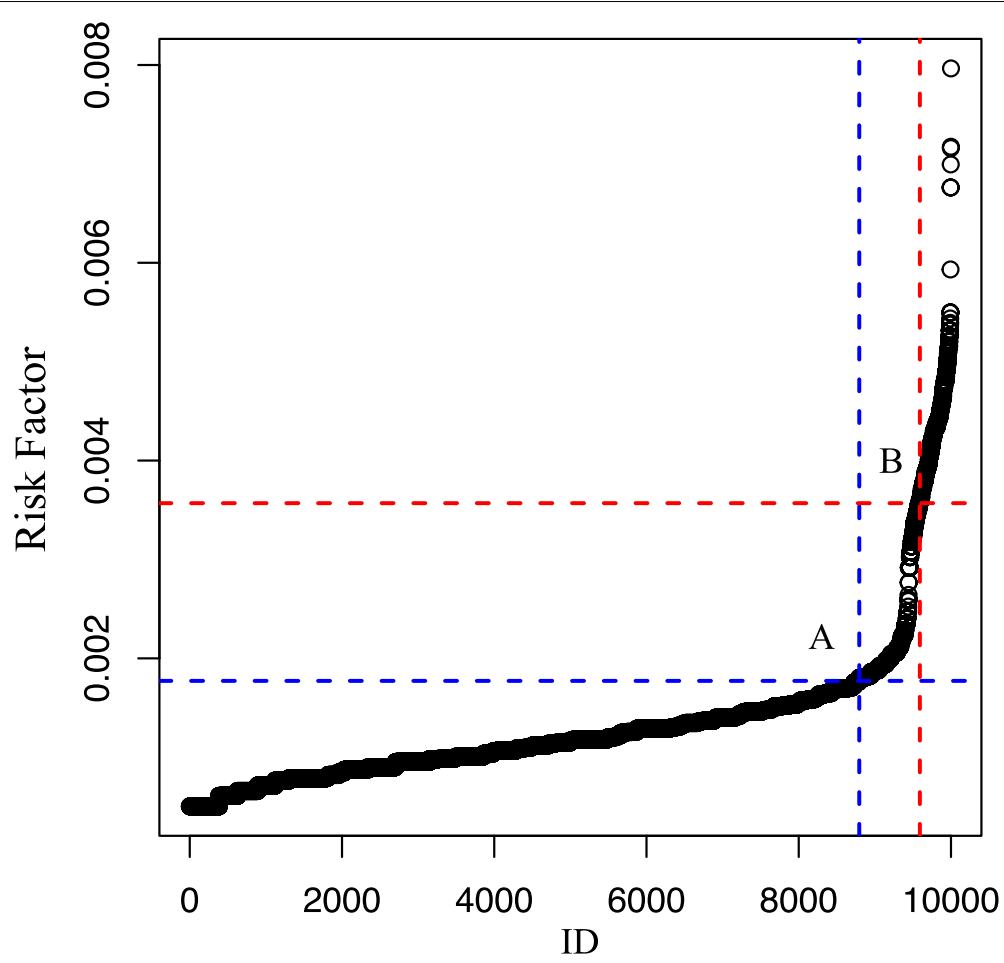

Fig. 2 The predictive analysis of Rothman-Keller model for EOCRC

\section{Conclusions}

We established a risk appraisal model for EOCRC based on meta-analysis and the Rothman-Keller model to provide personalized health education and screening for individuals with different risk levels, which can be used for primary prevention of CRC and to help reduce the incidence of EOCRC.

\section{Abbreviations}

EOCRC: Early-onset colorectal cancer; CRC: Colorectal cancer; WOS: Web of Science; SEER: Surveillance, Epidemiology, and End Results database.

\section{Supplementary Information}

The online version contains supplementary material available at https://doi. org/10.1186/s12885-022-09238-4.

Additional file 1. The individual risk scores of 10,000 simulated subjects.

\section{Acknowledgments}

Not applicable.

\section{Authors' contributions}

GJL and LY contributed to the concept, design, and writing of the manuscript. YJL, HM, and JY contributed to literature search, data acquisition, data analysis, and statistical analysis. $\mathrm{HCH}$ and LLC contributed to data acquisition, supervision, editing of the manuscript. HJG and WGL performed the manuscript review. All authors read and approved the final manuscript.

\section{Funding}

This work was supported by the National Natural Science Foundation of China (No. 82004288), Project of National Clinical Research Base of Traditional Chinese Medicine in Jiangsu Province (No. JD2019SZXYB04) and Jiangsu province TCM leading talent training project (No. SLJ0211).

\section{Availability of data and materials}

All data generated or analysed during this study are included in this published article [and its supplementary information files].

\section{Declarations}

Ethics approval and consent to participate

Not applicable.

\section{Consent for publication}

Not applicable.

\section{Competing interests}

The authors declare no conflicts of interest.

\section{Author details}

${ }^{1}$ Department of Oncology, Affiliated Hospital of Integrated Traditional Chinese and Western Medicine, Nanjing University of Chinese Medicine, 100 Cross Street, Maigaogiao, Nanjing, Jiangsu 210028, P.R. China. ${ }^{2}$ Nanjing University of Chinese Medicine, Nanjing 210046, Jiangsu, China. ${ }^{3}$ Department of Oncology, Jiangsu Province Academy of Traditional Chinese Medicine, Nanjing 210028, Jiangsu, China. ${ }^{4}$ Nanjing Lishui District Hospital of Traditional Chinese Medicine, Nanjing 211200, Jiangsu, China. ${ }^{5}$ Yangzhou University Medical College, Yangzhou 225000, Jiangsu, China.

Received: 18 August 2021 Accepted: 20 January 2022

Published online: 29 January 2022 


\section{References}

1. Sung H, Ferlay J, Siegel RL, Laversanne M, Soerjomataram I, Jemal A, et al. Global Cancer statistics 2020: GLOBOCAN estimates of incidence and mortality worldwide for 36 cancers in 185 countries. CA Cancer J Clin. 2021;71(3):209-49.

2. Mauri G, Sartore-Bianchi A, Russo AG, Marsoni S, Bardelli A, Siena S. Early-onset colorectal cancer in young individuals. Mol Oncol. 2019;13(2):109-31.

3. Virostko J, Capasso A, Yankeelov TE, Goodgame B. Recent trends in the age at diagnosis of colorectal cancer in the US National Cancer Data Base, 2004-2015. Cancer. 2019;125(21):3828-35.

4. Vuik FE, Nieuwenburg SA, Bardou M, Lansdorp-Vogelaar I, Dinis-Ribeiro M, Bento MJ, et al. Increasing incidence of colorectal cancer in young adults in Europe over the last 25 years. Gut. 2019;68(10):1820-6.

5. Myers EA, Feingold DL, Forde KA, Arnell T, Jang JH, Whelan RL. Colorecta cancer in patients under 50 years of age: a retrospective analysis of two institutions' experience. World J Gastroenterol. 2013;19(34):5651-7.

6. Yeo H, Betel D, Abelson JS, Zheng XE, Yantiss R, Shah MA. Early-onset colorectal Cancer is distinct from traditional colorectal Cancer. Clin Colorectal Cancer. 2017:16(4):293-299 e296.

7. Archambault AN, Lin Y, Jeon J, Harrison TA, Bishop DT, Brenner H, et al. Nongenetic determinants of risk for early-onset colorectal Cancer. JNCI Cancer Spectr. 2021;5(3):pkab029.

8. Elangovan A, Skeans J, Landsman M, Ali SMJ, Elangovan AG, Kaelber DC, et al. Colorectal Cancer, age, and obesity-related comorbidities: a large database study. Dig Dis Sci. 2020;66(9):3156-63.

9. Rosato V, Bosetti C, Levi F, Polesel J, Zucchetto A, Negri E, et al. Risk factors for young-onset colorectal cancer. Cancer Causes Control. 2013:24(2):335-41.

10. Nguyen LH, Liu PH, Zheng X, Keum N, Zong X, Li X, et al. Sedentary behaviors, TV viewing time, and risk of young-onset colorectal Cancer. JNCl Cancer Spectr. 2018;2(4):pky073.

11. Sondergaard G, Mortensen LH, Andersen AM, Andersen PK, Dalton SO, Osler M. Social inequality in breast, lung and colorectal cancers: a sibling approach. BMJ Open. 2013;3(3):e002114.

12. Fedewa SA, Siegel RL, Goding Sauer A, Bandi P, Jemal A. Colorectal cancer screening patterns after the American Cancer Society's recommendation to initiate screening at age 45 years. Cancer. 2020;126(6):1351-3.

13. Ladabaum U, Mannalithara A, Meester RGS, Gupta S, Schoen RE. Cost-effectiveness and National Effects of initiating colorectal Cancer screening for average-risk persons at age 45 years instead of 50 years. Gastroenterology. 2019;157(1):137-48.

14. O'Sullivan DE, Sutherland RL, Town S, Chow K, Fan J, Forbes N, et al. Risk factors for early-onset colorectal Cancer: a systematic review and Metaanalysis. Clin Gastroenterol Hepatol. 2021;S1542-3565(21):00087-2.

15. Breau G, Ellis U. Risk factors associated with young-onset colorectal adenomas and Cancer. A systematic review and Meta-analysis of observational research. Cancer Control. 2020:27(1):1073274820976670.

16. Rainey $L$, van der Waal D, Wengstrom Y, Jervaeus A, Broeders MJM. Women's perceptions of the adoption of personalised risk-based breast cancer screening and primary prevention: a systematic review. Acta Oncol. 2018:57(10):1275-83.

17. Bramer WM. Reference checking for systematic reviews using endnote. J Med Libr Assoc. 2018;106(4):542-6.

18. Rothman K, Keller A. The effect of joint exposure to alcohol and tobacco on risk of cancer of the mouth and pharynx. J Chronic Dis. 1972;25(12):711-6.

19. Wang B, Shen T, Mao L, Xie L, Fang QL, Wang XP. Establishment of a risk prediction model for mild cognitive impairment among elderly Chinese. J Nutr Health Aging. 2020;24(3):255-61.

20. Viera AJ. Odds ratios and risk ratios: what's the difference and why does it matter? South Med J. 2008;101(7):730-4.

21. Zhang J, Yu KF. What's the relative risk? A method of correcting the odds ratio in cohort studies of common outcomes. JAMA 1998;280(19):1690-1.

22. Schumacher AJ, Chen Q, Attaluri V, McLemore EC, Chao CR. Metabolic risk factors associated with early onset colorectal adenocarcinoma: a casecontrol study at Kaiser Permanente Southern California. Cancer Epidemiol Biomark Prev. 2021;30(10):1792-8 cebp.1127.2020.
23. Chang VC, Cotterchio M, De P, Tinmouth J. Risk factors for early-onset colorectal cancer: a population-based case-control study in Ontario, Canada. Cancer Causes Control. 2021:32(10):1063-83.

24. Low EE, Demb J, Liu L, Earles A, Bustamante R, Williams CD, et al. Risk factors for early-onset colorectal Cancer. Gastroenterology. 2020;159(2):492501 e497.

25. Gausman V, Dornblaser D, Anand S, Hayes RB, O'Connell K, Du M, et al. Risk factors associated with early-onset colorectal Cancer. Clin Gastroenterol Hepatol. 2020;18(12):2752-9 e2752.

26. Chen H, Zheng X, Zong X, Li Z, Li N, Hur J, et al. Metabolic syndrome, metabolic comorbid conditions and risk of early-onset colorectal cancer. Gut. 2021;70(6):1147-54.

27. Syed AR, Thakkar P, Horne ZD, Abdul-Baki H, Kochhar G, Farah K, et al. Old vs new: risk factors predicting early onset colorectal cancer. World J Gastrointest Oncol. 2019;11(11):1011-20.

28. Peters RK, Garabrant DH, Yu MC, Mack TM. A case-control study of occupational and dietary factors in colorectal cancer in young men by subsite. Cancer Res. 1989:49(19):5459-68.

29. Hofseth LJ, Hebert JR, Chanda A, Chen H, Love BL, Pena MM, et al. Earlyonset colorectal cancer: initial clues and current views. Nat Rev Gastroenterol Hepatol. 2020;17(6):352-64.

30. Akimoto N, Ugai T, Zhong R, Hamada T, Fujiyoshi K, Giannakis M, et al. Rising incidence of early-onset colorectal cancer - a call to action. Nat Rev Clin Oncol. 2021;18(4):230-43.

31. Silla IO, Rueda D, Rodriguez Y, Garcia JL, de la Cruz VF, Perea J. Early-onset colorectal cancer: a separate subset of colorectal cancer. World J Gastroenterol. 2014;20(46):17288-96.

32. Kirzin S, Marisa L, Guimbaud R, De Reynies A, Legrain M, Laurent-Puig $P$, et al. Sporadic early-onset colorectal Cancer is a specific sub-type of Cancer: a morphological, molecular and genetics study. PLoS One. 2014:9(8):e103159.

33. Bailey CE, Hu CY, You YN, Bednarski BK, Rodriguez-Bigas MA, Skibber JM, et al. Increasing disparities in the age-related incidences of colon and rectal cancers in the United States, 1975-2010. JAMA Surg. 2015;150(1):17-22

34. O'Connell JB, Maggard MA, Liu JH, Etzioni DA, Livingston EH, Ko CY. Do young colon cancer patients have worse outcomes? World J Surg. 2004;28(6):558-62.

35. Tan KK, Lopez V, Wong ML, Koh GC. Uncovering the barriers to undergoing screening among first degree relatives of colorectal cancer patients: a review of qualitative literature. J Gastrointest Oncol. 2018;9(3):579-88.

36. Tan KK, Lim TZ, Chan DKH, Chew E, Chow WM, Luo N, et al. Getting the first degree relatives to screen for colorectal cancer is harder than it seems-patients' and their first degree relatives' perspectives. Int J Color Dis. 2017;32(7):1065-8.

37. Kaminski MF, Polkowski M, Kraszewska E, Rupinski M, Butruk E, Regula J. A score to estimate the likelihood of detecting advanced colorectal neoplasia at colonoscopy. Gut. 2014;63(7):1112-9.

38. Rank KM, Shaukat A. Stool based testing for colorectal Cancer: an overview of available evidence. Curr Gastroenterol Rep. 2017;19(8):39.

39. Sun M, Liu J, Hu H, Guo P, Shan Z, Yang H, et al. A novel panel of stoolbased DNA biomarkers for early screening of colorectal neoplasms in a Chinese population. J Cancer Res Clin Oncol. 2019:145(10):2423-32.

40. Church TR, Wandell M, Lofton-Day C, Mongin SJ, Burger M, Payne SR, et al. Prospective evaluation of methylated SEPT9 in plasma for detection of asymptomatic colorectal cancer. Gut. 2014;63(2):317-25.

41. Murphy CC. Colorectal Cancer in the young: does screening make sense? Curr Gastroenterol Rep. 2019;21(7):28.

42. Mehta SS, Arroyave WD, Lunn RM, Park YM, Boyd WA, Sandler DP. A prospective analysis of red and processed meat consumption and risk of colorectal Cancer in women. Cancer Epidemiol Biomark Prev. 2020;29(1):141-50.

43. Zahnd WE, Gomez SL, Steck SE, Brown MJ, Ganai S, Zhang J, et al. Ruralurban and racial/ethnic trends and disparities in early-onset and averageonset colorectal cancer. Cancer. 2021;127(2):239-48.

44. Muller C, Ihionkhan E, Stoffel EM, Kupfer SS. Disparities in Early-Onset Colorectal Cancer. Cells. 2021;10(5):1018.

45. Siegel RL, Medhanie GA, Fedewa SA, Jemal A. State variation in earlyonset colorectal Cancer in the United States, 1995-2015. J Natl Cance Inst. 2019:111(10):1104-6. 
46. Marley AR, Nan H. Epidemiology of colorectal cancer. Int J Mol Epidemiol Genet. 2016;7(3):105-14.

47. Zhang L, Cao F, Zhang G, Shi L, Chen S, Zhang Z, et al. Trends in and predictions of colorectal Cancer incidence and mortality in China from 1990 to 2025. Front Oncol. 2019;9(98):98.

48. Patel P, De P. Trends in colorectal cancer incidence and related lifestyle risk factors in 15-49-year-olds in Canada, 1969-2010. Cancer Epidemiol. 2016:42:90-100.

49. Wang L, Gao P, Zhang M, Huang Z, Zhang D, Deng Q, et al. Prevalence and ethnic pattern of diabetes and Prediabetes in China in 2013. JAMA. 2017;317(24):2515-23.

50. Ordonez-Mena JM, Walter V, Schottker B, Jenab M, O'Doherty MG, Kee F, et al. Impact of prediagnostic smoking and smoking cessation on colorectal cancer prognosis: a meta-analysis of individual patient data from cohorts within the CHANCES consortium. Ann Oncol. 2018;29(2):472-83.

51. Cai S, Li Y, Ding Y, Chen K, Jin M. Alcohol drinking and the risk of colorectal cancer death: a meta-analysis. Eur J Cancer Prev. 2014;23(6):532-9.

52. Triantafillidis JK, Nasioulas G, Kosmidis PA. Colorectal cancer and inflammatory bowel disease: epidemiology, risk factors, mechanisms of carcinogenesis and prevention strategies. Anticancer Res. 2009;29(7):2727-37.

53. Zheng X, Hur J, Nguyen LH, Liu J, Song M, Wu K, et al. Comprehensive assessment of diet quality and risk of precursors of early-onset colorectal Cancer. J Natl Cancer Inst. 2021;113(5):543-52.

\section{Publisher's Note}

Springer Nature remains neutral with regard to jurisdictional claims in published maps and institutional affiliations.

- fast, convenient online submission

- thorough peer review by experienced researchers in your field

- rapid publication on acceptance

- support for research data, including large and complex data types

- gold Open Access which fosters wider collaboration and increased citations

- maximum visibility for your research: over $100 \mathrm{M}$ website views per year

At BMC, research is always in progress.

Learn more biomedcentral.com/submissions 